\title{
Removing Barriers to Utility Interconnected Photovoltaic Inverters
}

\author{
Sigifredo Gonzalez, Russell Bonn, Jerry Ginn, Sandia National Laboratories Albuquerque, NM 87185-0753
}

\begin{abstract}
The Million Solar Roofs Initiative has motivated a renewed interest in the development of utility interconnected photovoltaic (UIPV) inverters. Government-sponsored programs (PVMaT, PV:BONUS) and competition among utility interconnected inverter manufacturers have stimulated innovations and improved the performance of existing technologies. With this resurgence, Sandia National Laboratories (SNL) has developed a program to assist industry initiatives to overcome barriers to UIPV inverters. In accordance with newly adopted IEEE 929-2000, the utility interconnected PV inverters are required to cease energizing the utility grid when either a significant disturbance occurs or the utility experiences an interruption in service [5]. Compliance with IEEE 929-2000 is being widely adopted by utilities as a minimum requirement for utility interconnection. This report summarizes work done at the SNL balance-of-systems laboratory to support the development of IEEE 929-2000 and to assist manufacturers in meeting its requirements.

\section{INTRODUCTION}

Utility compatibility is a major issue with the implementation of UIPV static inverters. The focus of the concern has been primarily on the inverters' ability to detect an abnormal condition on the utility grid and take appropriate actions to ensure the safety of personnel and to maintain the high reliability of utility equipment. The abnormal conditions are defined in detail in the newly adopted IEEE 929-2000 IEEE Recommended Practice for Utility Interface of Photovoltaic (PV) Systems. Presently SNL is assisting UIPV static inverter manufacturers to meet the interconnection issues that are addressed in IEEE 929-2000.

SNL has conducted extensive anti-islanding testing to support the development of IEEE $929-2000$ and to monitor the performance of grid-tied inverters [2]. SNL has contracted with UIPV static inverter manufacturers to develop and implement solid-state circuitry that both meets the IEEE 929-2000 requirements and increases the reliability and performance of the UIPV static inverters. To analyze the validity of the anti-islanding techniques, a standardized anti-islanding test procedure was developed at SNL and incorporated into IEEE 929-2000 Annex A. This recommended test procedure specifies the methods by which the tests for the RLC $60-\mathrm{Hz}$ resonant circuit are conducted.

\section{ISLANDING}

The condition referred to as an island occurs when a residential distributed generation source continues to energize a portion of the utility grid after the utility experiences an interruption in service. The concern is that the utility no longer controls this isolated portion of the distribution system, consisting of a PV generation source and local loads. Therefore, an islanding occurrence may compromise safety, restoration of service, and equipment reliability.

For an island condition to occur, the situation must be such that the inverter does not recognize an interruption in utility service. If the loads that remain on the isolated portion of the grid are closely matched to the output of the inverter, it is possible for voltage and frequency to remain relatively constant after the interruption in utility power. Anti-islanding schemes that depend on only monitoring the voltage and frequency may not detect this condition, and continue energizing the utility thus creating an island.

Significant prior work on PV-inverter islanding was done at SNL in the 1980s [1]. Since that time, inverter technology has evolved significantly, and a new generation of products has appeared. Renewed interest (spurred partially by the Million Solar Roofs Initiative) made it necessary to evaluate the performance of the present generation of grid-tied inverters with particular emphasis on the islanding issue. Most of the new generation of utility interconnect photovoltaic inverters are able to identify when the utility has experienced an interruption in service when connected to a dedicated UIPV inverter interactions with several inverters connected to the same feeder.

\section{Multi-Inverter Test}

To address this concern, a test bed was created to investigate the operation of multiple inverters on the same ac circuit. The intent was to simulate a residential neighborhood having a high penetration of UIPV inverters. Figure 1 shows a one-line diagram of the multi-inverter test set-up. Up to five inverters from different manufacturers and of different types were placed on the same feeder. A variable resistive load was connected onto the same feeder and adjusted to closely match the total output power being generated by the inverters. The next step was to interrupt utility service. A motor start contactor was utilized to remove the utility and initiate the islanding test. A current transformer on each of the UIPV inverters' output was used to identify when the inverter ceased to invert and to monitor its pre-interruption operating condition. An oscilloscope waveform captures 


\section{DISCLAIMER}

This report was prepared as an account of work sponsored by an agency of the United States Government. Neither the United States Government nor any agency thereof, nor any of their employees, make any warranty, express or implied, or assumes any legal liability or responsibility for the accuracy, completeness, or usefulness of any information, apparatus, product, or process disclosed, or represents that its use would not infringe privately owned rights. Reference herein to any specific commercial product, process, or service by trade name, trademark, manufacturer, or otherwise does not necessarily constitute or imply its endorsement, recommendation, or favoring by the United States Government or any agency thereof. The views and opinions of authors expressed herein do not necessarily state or reflect those of the United States Government or any agency thereof. 


\section{DISCLAIMER}

Portions of this document may be illegible in electronic image products. Images are produced from the best available original document. 
the output current from each of the UIPV inverters as well as the feeder voltage. This acquisition is triggered by a signal from the contactors' control contacts. The run-on time was calculated from the opening of the contactor until the current output of each inverter decreased to approximately 0.1 amp peak. This test represents a nofault disconnect since the voltage and frequency are within the operating ranges of the inverters prior to removal of the grid. For a no-fault condition and matched loads, IEEE 929-2000 allows up to 2 seconds for the UIPV inverter to identify the loss of utility and take appropriate action.

[Note that under fault conditions, the voltage and/or frequency will vary from the nominal state and the allowable disconnect duration varies from 2 cycles to 10 cycles depending on the severity of the disturbance. A fault-induced condition requires the UIPV inverter to disconnect from the utility much faster primarily so that the distributed generation will not interfere with utility hardware (automatic reclosers). Utility engineers involved in the development of IEEE 929-2000 have stated that run-on times greater than ten cycles ( 0.167 seconds) constitute a potential problem on systems equipped with automatic fault-clearing recioser equipment.]

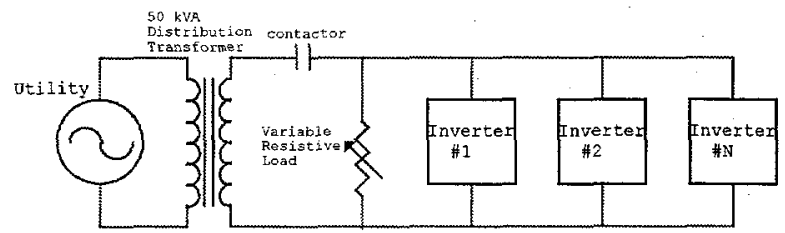

Figure 1. Multi-inverter Test Setup

The results of the multi-inverter islanding tests confirmed that if a utility feeder contains several utility interconnected photovoltaic static inverters from different manufacturers, their anti-islanding techniques would have difficulty identifying the absence of the grid. This potential problem can only exist if the isolated portion of the circuit has a load that absorbs the power being generated by the inverters. The variables that make the islanding conditions possible are a function of the types of loads connected to the isolated portion of the utility and the magnitude of loads attached. If the power being generated by the UIPV sources is approximately the same as the load, then the chance for inverter run-on increases significantly. Figure 2 shows the results of one set of multi-inverter tests. For these particular tests, the combined power from the inverters was approximately 6.6 $\mathrm{kW}$ and the resistive load was approximately $6.6 \mathrm{~kW}$. The abscissa of Figure 2 is the ratio of inverter power generated to that of the resistive load (Pgen/Pload). Figure 2 shows that the required 2 second disconnect time was exceeded frequently in the multi-inverter test. As noted, two of the tests resulted in continuous run-ons and required operator intervention to stop the run-on.

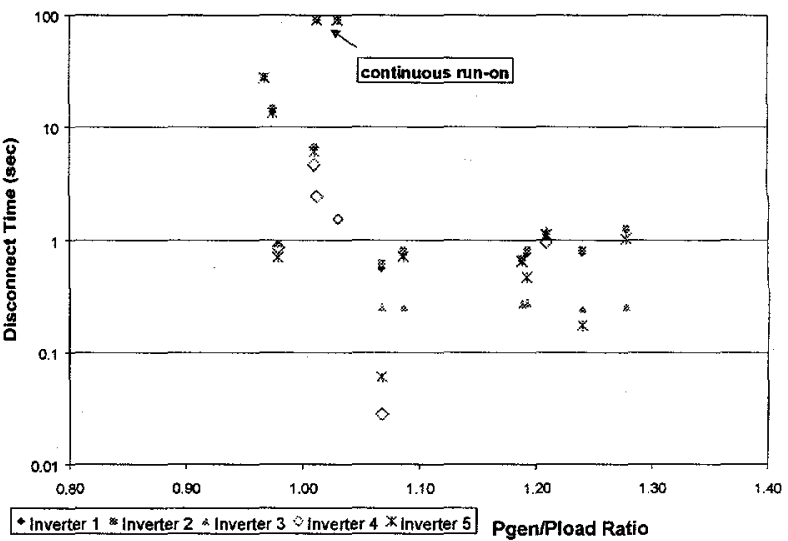

Figure 2. Multi-inverter Islanding Test

\section{Development of A New Anti-lslanding Approach}

After a number of sets of islanding tests were performed, it became apparent that if multiple PV inverters from different inverter manufacturers existed on the same feeder line, the possibility of a run-on increased significantly. The islanding test results were distributed to manufacturers of UIPV inverters. The manufacturers acknowledged the islanding issue as an obstacle that plagued all UIPV inverters and agreed to meet at SNL to discuss the results of the multi-inverter islanding tests.

An anti-islanding working group meeting was held at SNL in November of 1997. It was agreed that (1) different anti-islanding methodologies in inverters on a common ac feed interfered with one another, and (2) it was important to develop a non-interfering method that all manufacturers could choose to implement in their products. It was further recognized that passive detection schemes such as over/under frequency detection and over/under voltage detection would not avoid the potential multi-inverter interference issue and were inadequate in preventing islanding under certain conditions.

By consensus, Ascension Technologies was chosen to develop an anti-islanding approach that utilizes an active scheme to continuously attempt to accelerate any deviations in the operating frequency and voltage of the utility. The new anti-islanding technique was developed under contract to SNL and become public domain for other manufacturers to utilize [2]. The method that was developed was the Sandia frequency shift (SFS) in combination with the Sandia voltage shift (SVS).

The SFS method works by shifting the output current frequency as a function of the system's frequency deviations. The system frequency is monitored on a subcycle basis. A feedback loop shifts the frequency in the direction of the deviation, whether it be positive or negative. This allows the system frequency to be shifted rapidly outside a preset frequency window during the absence of the utility.

The SVS method measures system voltage on a subcycle basis. Depending on the nature of the deviation and amount of deviation, the feedback loop in effect shifts the power out of the inverter. If the utility is absent then the voltage can be shifted rapidly outside a preset voltage-

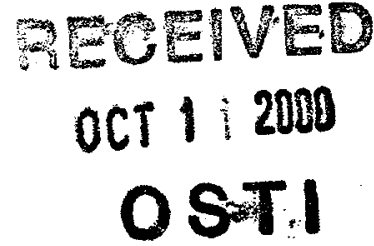


operating window causing the inverter to quickly shutdown.

\section{Single-Inverter Tests}

A single-inverter test was needed to independently validate the variety of anti-islanding techniques offered by the different manufacturers. One stipulation for the single-inverter test would be repeatability regardless of where the test was conducted. This was desired primarily so manufacturers could conduct the same type of islanding test as was conducted at SNL and obtain the same results without having to utilize specialized equipment.' With this in mind, passive RLC components were utilized for the single-inverter islanding test configuration. The two energy-storage components could easily be adjusted to resonate at $60 \mathrm{~Hz}$. It was recognized that motor loads could also lead to islanding durations exceeding the no-fault disconnect requirement; however, testing at SNL indicated that RLC loads were as difficult to detect. Resonant RLC loads constituted a simpler test configuration that was more easily reproducible than one involving motors.Figure 3 shows a one-line diagram for the single-inverter islanding test.

Another reason the single-inverter test was desired was to reduce the complexity that would be associated with multi-inverter testing. A multi-inverter test would require choices of the types and numbers of inverters to include in the test bed. This would make repeatable onsite testing by manufacturers very difficult. The singleinverter islanding test has recently been adopted by Underwriters Laboratories [3].

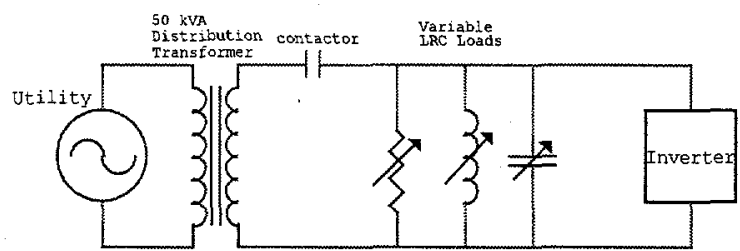

Figure 3. RLC Islanding Test Configuration

\section{Single-Inverter Islanding Test Procedure}

When the utility has been disconnected, if the isolated local loads are not balanced with the UIPV inverter generation, the voltage or the frequency will quickly shift outside the normal operating window of the UIPV inverter. However, loads that closely match the real and reactive power generated by the UIPV inverter would define a "non-detection zone" that could result in islanding [4]. The circuit that was selected as being most likely to expose the non-detection zone of any inverter is shown in Figure 3. It consists of an RLC circuit that is resonant at $60 \mathrm{~Hz}$ and has a load power closely matched to the output of the inverter (Pgen/Pload $\cong 1$ ). This is a difficult case to detect because neither voltage nor frequency changes when the grid is removed. The critical parameter in setting up the test circuit is the quality factor (Q) .

Unfortunately, the term $Q$ can be confusing because it is used for two different quantities in electrical engineering. It is commonly known as the reactive component in the complex power equation $S=P+j Q$. It also signifies the quality factor of a circuit. This parameter is defined as $2 \pi$ times the ratio of the maximum stored energy at resonant frequency to the energy dissipated per cycle at that resonant frequency. When the loads are connected as shown in Figure 3 (parallel) the value of $Q$ is:

$$
\mathrm{Q}=\mathrm{R} \sqrt{C / L}
$$

Or when real power $P$ and reactive powers, var, (inductive loads) and $\operatorname{var}_{c}$ (capacitive loads) are known the equation for $Q$ is:

$$
\mathrm{Q}=(1 / \mathrm{P}) \sqrt{\operatorname{var}_{c} \times \operatorname{var}_{L}}
$$

If $\operatorname{var}_{C}=\operatorname{var}_{\mathrm{L}}$ then equation 2 simplifies to:

$$
Q=\operatorname{var} / P
$$

$$
\text { where } \operatorname{var}=\operatorname{var}_{\mathrm{C}}=\operatorname{var} \mathrm{L}
$$

The significance of $Q$ in defining a non-islanding inverter is crucial. The higher the $Q$ values the stronger the tendency to move toward or stay at the resonant frequency. Therefore, the value of $Q$ must be realistic. Using $Q=\tan (\operatorname{arccosine}[\mathrm{pf}])$ the values of $Q$ from 0 to 2.5 are associated with uncorrected power factors from 0.37 to unity and therefore represent all reasonable distribution line configurations [5].

\section{Single Inverter Test Results}

The effectiveness of the RLC test is illustrated in Figure 4. For these tests a UIPV inverter having a new generation of anti-islanding circuitry but without SFS/SVS was tested using a resistive load and a $60 \mathrm{~Hz}$ resonant load. The inverter had no difficulty detecting the absence of the utility when the local load was only a resistive load, yet failed to detect the absence of the utility with the 60 $\mathrm{Hz}$ resonant $\mathrm{RLC}$ load with a $\mathrm{Q}$ factor slightly less than 2.5 .

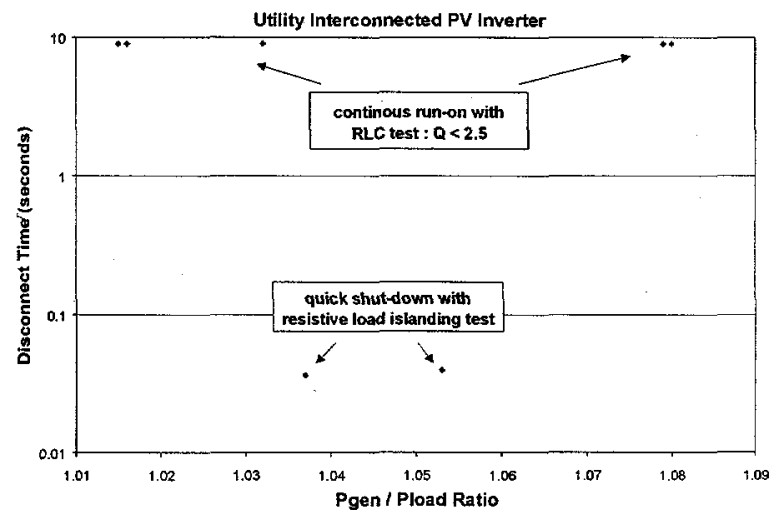

Figure 4. Disconnect Times of an Islanding Inverter for Resistive-only and RLC Load Tests

The RLC test was performed on another UIPV inverter utilizing the SFS/SVS anti-islanding method. The load for this test was a RLC load with a $Q$ factor of $\approx 2.5$. Figure 5 shows the data recorded during a routine islanding test. The system voltage and inverter current are shown before and after the utility is removed. The 
utility is removed 100 milliseconds into the acquisition. The inverter stops supplying current about 8 cycles after removal of the grid.

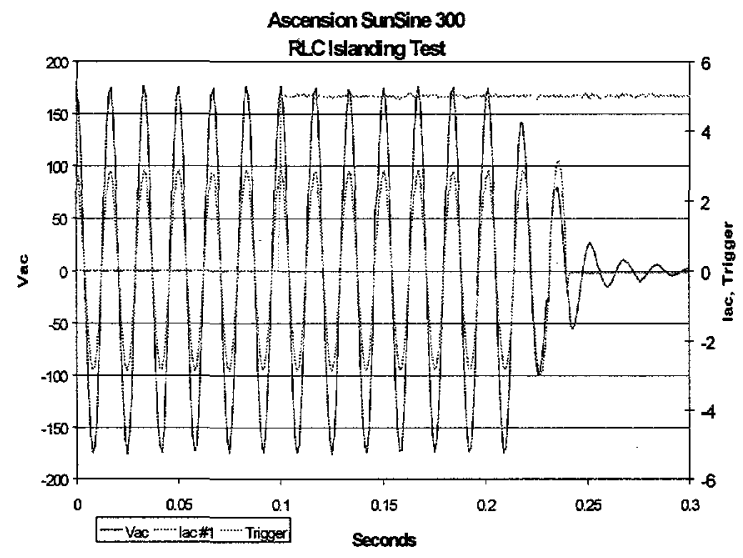

Figure 5. RLC Islanding Test of inverter with SFS/SVS

\section{Additional Tests}

The single inverter test provides a means of determining the adequacy of the anti-islanding techniques of a UIPV inverter. Since utilities throughout the nation are adopting the IEEE 929-2000 IEEE Recommended Practice for Utility Interface of Photovoltaic (PV) Systems as their UIPV inverter interconnection requirement, more manufacturers will design and implement their own version of the SFS/SVS anti-islanding technique in their product. Sandia plans are to acquire these products, conduct multi-inverter tests, and publish the results.

\section{SUMMARY}

Utility interconnected photovoltaic inverters will overcome implementation opposition if a technique can reliably detect abnormal utility conditions and take the measures necessary to insure that safety, restoration of service, and equipment reliability are not compromised. A technique that monitors the system frequency and voltage on sub-cycle bases and attempts to accelerate any deviation has been shown to effectively identify the absence of the utility.

To assist UIPV static inverter manufacturers to compete with foreign manufacturers, the single-inverter anti-islanding test plan provides a feasible method of conducting in-house device testing and will identify an inverter unable to pass IEEE $929-2000$ or UL 1741 antiislanding criteria. This will also assist UIPV inverter manufacturers to overcome potential interconnection barriers as more and more utilities adopt IEEE 929-2000 as their interconnection requirement. The single inverter anti-islanding test also provides a reasonable method for evaluating design modifications to existing methods or validating innovative methods.

\section{REFERENCES}

[1] John Stevens, "Utility Intertied Photovoltaic System Islanding Experiments," Proceedings of the Nineteenth IEEE Photovoltaic Specialists Conference, New Orleans, Louisiana, May 4-8, 1987.

[2] Kern, G. A., Bonn, R., Ginn, J., Gonzalez, S., "Results of SNL Grid-Tied Inverter Testing," Proceedings, $2^{\text {nd }}$ World Conference and Exhibition on Photovoltaic Solar Energy Conversion, Vienna, Austria, July 1998.

[3] UL Standard for Safety for Static Converters and Charge Controllers for Use in Photovoltaic Power Systems, UL1741, Underwriters Laboratories, First Edition, May 7, 1999.

[4] Begovic, M., Ropp, M., Rohatgi, A., Pregelj, A., "Determining the Sufficiency of Standard Protective Relaying for Islanding Prevention in Grid-Connected PV Systems," Proceedings, $2^{\text {nd }}$ World Conference and Exhibition on Photovoltaic Solar Energy Conversion, Vienna, Austria, July 1998.

[5] IEEE 929-2000 Recommended Practice for Utility Interface of Photovoltaic (PV) Systems, Sponsored by IEEE Standards Coordinating Committee 21 on Photovoltaics, IEEE Std 9292000. Published by the IEEE, New York, NY April 2000.

\section{ACKNOWLEDGMENT}

Sandia National Laboratories is a multiprogram laboratory operated by Sandia Corporation, a Lockheed Martin Company, for the United States Department of Energy under Contract DE-AC04-94AL85000. 